\title{
ПИСЬМА ОРГАНОВ ИСПОЛНИТЕЛЬНОЙ ВЛАСТИ: ПРОБЛЕМЫ ОПРЕДЕЛЕНИЯ, ЮРИДИЧЕСКОЙ ПРИРОДЫ И СООТНОШЕНИЯ С НОРМАТИВНЫМИ АКТАМИ
}

\begin{abstract}
Аннотация. Объектом настоящего исследования являются письма органов исполнительной власти Российской Федерации. Предмет настоящей работы заключается в исследовании юридической природы писем федеральных министерств, служб и агентств, определение его отличительных признаков и практические проблемы, возникающие при их практической реализации в различных правоотношениях. Особое внимание уделяется как теоретическим вопросам писем (их особенностей, отличий от нормативных правовых актов), так и анализу судебной практики по спорам, связанным с применением данных актов. При написании данной научной работы авторами использовались общенаучные методы исследования (всеобщий диалектический метод, анализ, синтез, системный подход), а также частноправовые (формально-юридический и сравнительно-правовой). Новизна проведенного исследования состоит прежде всего в том, что впервые автором детально анализируется как теоретические вопросы юридической сущности писем, поскольку теорией права они абсолютно не изучены и нет никаких работ, посвященных данной тематике. Помимо этого, особый вклад автором в исследование является изучение практических проблем, связанных с их применением при регулировании правоотношений.

Ключевые слова: Нормативный правовой акт, официальные письма, органы исполнительной власти, постановления Правительства, правотворчество, судебная практика, исполнительная власть, судебная власть, проект закона, правосудие.

Abstract. The research object includes the letters of executive authorities of the Russian Federation. The research subject is the study of the legal nature of letters of federal ministries, services and agencies, the definition of their distinguishing features and the practical problems of their implementation in various legal relations. Special attention is paid to theoretical aspects of letters (their peculiarities and differences from statutory acts), and the analysis of judicial practice related to their application. The author applies general scientific methods (the dialectical method, analysis, synthesis, the system approach), and specific methods (formal-legal and comparative-legal). The scientific novelty of the study consists in the first attempt to analyze the theoretical aspects of the legal essence of letters, since they haven't been studied by the theory of law yet. Besides, the author studies the practical aspects of their application in the regulation of legal relationship.

Key words: justice, draft law, judicial authority, executive authority, judicial practice, lawmaking, governmental decrees, executive authorities, official letters, statutory instrument.
\end{abstract}

$\mathrm{H}$ ормативный правовой акт (далее по тексту НПА) в современной России является основным источником правового регулирования общественных отношений. Законодательное определение НПА отсутствует, но в рамках настоящей статьи представляется вполне уместным использование дефиниции, данной в Приказе Министерства Юстиции Российской Федерации от 04.05.2007 г. № 88 «Об утверждении Разъяснений о применении Правил подготовки нормативных правовых актов федеральных органов исполнительной власти и их государственной регистрации». В соответствии с данным актом, «Нормативный правовой акт - это письменный официальный документ, принятый (изданный) в определенной форме правотворческим органом в пределах его компетенции и направленный на установление, изменение или отмену правовых норм. В свою очередь, под правовой нормой принято понимать общеобязательное го- сударственное предписание постоянного или временного характера, рассчитанное на многократное применение» ${ }^{[4]}$.

Также не будет лишним отметить, что в Постановлении Правительства Российской Федерации от 13 августа 1997 г. N 1009 «Об утверждении Правил подготовки нормативных правовых актов федеральных органов исполнительной власти и их государственной регистрации» (далее по тексту Постановление Правительства N 1009) говорится, что «нормативные правовые акты федеральных органов исполнительной власти издаются только в виде постановлений, приказов, распоряжений, правил, инструкций и положений». А также отмечается, что «Издание нормативных правовых актов в виде писем и телеграмм не допускается» ${ }^{[3]}$.

Прежде, чем перейти к более детальному рассмотрению проблемы, стоит перечислить основные признаки НПА. Так, М. Н. Марченко в своем 


\section{Административное и муниципальное право 7 (103) • 2016}

учебном пособии по теории государства и права дает следующий перечень признаков НПА:

«1. Все без исключения нормативно-правовые акты являются государственными по своему характеру.

2. Они издаются или санкционируются только органами государства, имеют волевой характер.

3. В них содержится и через них преломляется государственная воля.

4. С нарушением велений, содержащихся в нормативно-правовых актах, связывается наступление уголовно-правовых, гражданско-правовых и иных юридических последствий». [6, С. 170].

Также к этим признакам можно добавить неперсонифицированный характер НПА (их адресованность неопределённому кругу лиц); то, что они создаются для многократного применения и направлены на регулирование общественных отношений; имеют определенную процедуру принятия, опубликования и вступления в силу.

Вопрос о признаках в данной статье имеет большое значение, так как определение письма и его характерных черт в современной юридической науке отсутствует. А учитывая то, что эти документы издаются органами исполнительной власти и де-факто обладают некоторыми признаками НПА, то стоит разобраться, являются ли они таковыми или нет.

По идее, решить возникший вопрос должна помочь судебная практика, связанная с оспариванием писем, издаваемых различными органами исполнительной власти. Но она весьма противоречива. Проиллюстрировать это можно на следующих примерах.

По одному из дел, рассмотренному в Верховном Суде Российской Федерации (далее по тексту Верховный Суд) в 2014, гражданин Д. Н. Ирхин (далее по тексту - заявитель) был лишен должности кадастрового инженера комиссией по аттестации в связи с грубым нарушением требований оформления документов, необходимых для получения квалификационного аттестата на право осуществления кадастровой деятельности. Причем основанием для такого решения комиссии по аттестации кадастровых инженеров явились не те грубые нарушения, которые перечислены в Федеральном законе «0 государственном кадастре недвижимости» (далее по тексту - закон о кадастре), а те, что содержались в Письме Министерства экономического развития Российской Федерации от 27.07.2010 г. «Об основаниях аннулирования квалификационного аттестата кадастрового инженера». Верховный Суд, проведя анализ данного акта, пришел к выводу, что «Письмо является нормативным правовым актом, поскольку содержит правовые нормы (правила поведения), обязательные для неопределенного круга лиц, рассчитанные на не- однократное применение, направленные на урегулирование общественных отношений, возникающих в связи с ведением государственного кадастра недвижимости, осуществлением государственного кадастрового учета недвижимого имущества и кадастровой деятельности» ${ }^{[5]}$.

После установления данного письма как НПА, Верховный Суд указал, что данное Письмо не представлялось на государственную регистрацию в Министерство Юстиции Российской Федерации (далее по тексту - МинЮст России) и не было опубликовано в установленном законом порядке, нарушило п. 2 Постановления Правительства N 1009, гласящего, что «Издание нормативных правовых актов в виде писем и телеграмм не допускается» ${ }^{[3]}$. И, как итог, удовлетворил требования заявителя и признал недействующим упомянутое Письмо Министерства экономического развития России, тем самым запретив его применение на практике.

Второй пример хоть и относится к отрасли налогового права, и все же там события получили совершенно другое развитие, нежели в первом случае. Речь пойдет о налогообложении на добычу полезных ископаемых в части их нормативных потерь.

По общему правилу, установленному действующим налоговым законодательством, налоговая ставка в данном случаем составляет $0 \%$ (рублей). Абз. 3 п. 1) ч. 1 ст 342 Налогового кодекса Российской Федерации устанавливает, что если на первый период очередного календарного года у налогоплательщиков отсутствуют утвержденные нормативы потерь на этот год, то применяется те нормативы, которые были утверждены ранее (а по вновь разрабатываемым месторождениям - нормативы потерь, установленные техническим проектом) ${ }^{[2]}$.

21.08.2013 г. Федеральная налоговая служба (далее по тексту - ФНС) опубликовало Письмо N AC4-3/15165 «0 налоге на добычу полезных ископаемых» (далее по тексту - Письмо ФНС «О НДПИ»). В нем, помимо того, что было написано абзацем выше, ФНС устанавливает правило перерасчета сумм налога на добычу полезных ископаемых в том случае, если нормативы потерь утверждены на очередной календарный год в течение этого, либо следующего за ним календарного года. Причем не важно, увеличатся эти нормативы или уменьшатся. К слову, во втором случае налогоплательщик не сможет заранее определить размеры своих расходов, что не лучшим образом повлияет на его деятельность.

Это все и послужило поводом для подачи заявления ОАО «Газпром нефть» (далее по тексту «Газпром нефть») в Верховный Суд. Определением от 17.12.2013 г. Верховный Суд отказал в принятии заявления «Газпром нефть» о признании недействительным Письма ФНС «О НДПИ».При этом Верховный Суд указал в своем определении, что 
рассмотрение вопросов об оспаривании НПА Федеральной налоговой службы подведомственно арбитражному суду.

Теперь, вспомнив предыдущий пример (про кадастрового инженера), где Письмо было признано НПА, можно только задаться вопросом о единстве судебной практики, которой, получается, вовсе нет. Причем все это проходило в рамках одного суда, что еще более удивительно. Теперь можно продолжить ход повествования.

После второго отказа от рассмотрения дела Высшим Арбитражным Судом Российской Федерации «Газпром нефть» обратилось в Конституционный Суд Российской Федерации (далее по тексту - Конституционный Суд) с оспариванием норм Федерального конституционного закона от 05.02.2015 г. «0 Верховном Суде Российской Федерации» и упомянутый выше абз. 3 п. 1) ч. 1 ст. 342 Налогового кодекса Российской Федерации. Но, учитывая предмет настоящей статьи, основное внимание будет уделено рассуждениям и решениям Конституционного Суда, связанными с юридической силой упомянутого выше Письма.

Конституционный Суд пояснил, что «...в основе допустимости проверки в данной процедуре акта Федеральной налоговой службы как федерального органа исполнительной власти прежде всего должно лежать наличие у этого акта нормативных свойств (оказывает ли он общерегулирующее воздействие на общественные отношения, содержатся ли в нем предписания о правах и обязанностях персонально не определенного круга лиц - участников соответствующих правоотношений, рассчитан ли он на многократное применение)» [1]. То есть, не просто проводить процедуру соответствия формальным признакам НПА, которую весьма противоречиво осуществлял Верховный Суд при рассмотрении дел, указанных выше, а именно способность НПА воздействовать на общественные отношения, иметь неперсонифицированный характер и быть рассчитанным на многократное применение.

Таким образом, с 2015 г. акты органов исполнительной власти, которые формально не являются НПА, но обладают нормативными свойствами, рассматриваются в порядке, установленном для оспаривания нормативных правовых актов. Но с марта 2016 года данный «переходный» порядок претерпит изменения, поскольку был принят Федеральный закон от 15 февраля 2016 г. N 18-ФЗ «0 внесении изменений в Арбитражный процессуальный кодекс Российской Федерации и Кодекс административного судопроизводства Российской Федерации в части установления порядка судебного рассмотрения дел об оспаривании отдельных актов». Согласно данному федеральному закону, арбитражные дела по оспариванию актов органов исполнительной власти, обладающих нормативными свойствами и содержащими разъяснения законодательства, будут рассматриваться в случае отнесения данной категории дел Арбитражным-процессуальным кодексом Российской Федерации к компетенции Суда по интеллектуальным правам. Более того, в Кодекс административного судопроизводства были внесены изменения, определяющие подсудность дел по поводу оспаривания актов вышеуказанных органов, разъясняющих положения законодательства и обладающие нормативными свойствами, а также процедуру производства по административным делам об оспаривании указанных актов.

Возвращаясь к анализу решения Конституционного Суда, в нем можно выделить следующие недостатки:

1. Несмотря на вполне обоснованную позицию Конституционного Суда, который акцентировал внимание на нормативных свойствах Писем ФНС, игнорировать формальные признаки не совсем правильно. Все-таки есть установленные Конституцией (ч. 3 ст. 15) и рядом других НПА требования и условия (форма самого документа, надлежащий субъект издания, порядок принятия и вступления в силу и т.д.), которые позволяют определить документ как нормативный правовой акт.

Весьма интересными в данном случае представляются Особые мнения судей Конституционного Суда Ю. М. Данилова и Г. А. Жилина, которые одинаково сошлись в том, что данные акты не являются нормативными правовыми и подлежат оспариванию в арбитражном суде в соответствии с Главой 24 Арбитражно-процессуального кодекса Российской Федерации ${ }^{[1]}$.

1. Прежде всего, Письмам ФНС был придан особый статус. С одной стороны, они не являются НПА в прямом значении этого термина. Но и ненормативными актами их назвать уже нельзя, так как рассматриваться судами они будут наравне с делами об оспаривании НПА. Способствует ли это непротиворечивой правоприменительной практике? Повышает ли это эффективность осуществления правосудия? Маловероятно...

Вообще вопросы соотношения актов толкования с нормативными актами в настоящее время приобрели особо острое значение. Это очевидно вытекает из приведенных примеров, где даже в высших судебных инстанциях нет единства мнений по возникшим вопросам. Конечно, Определение Конституционного Суда внесло больше ясности в разрешение названных вопросов, но не без недостатков, которые также были описаны выше.

При этом представляется, что игнорировать данную проблему ни в коем случае нельзя, так как в актах, которые изначально издавались органами 


\section{Административное и муниципальное право 7 (103) • 2016}

исполнительной власти с целью разъяснения конкретного закона (нормы закона), стали появляться нормы, не предусмотренные законом, но создающие определенные требования, правила поведения. И если у гражданина (организации) возникает ситуация (например, как в случае с гражданином Ирхиным), связанная с такими актами, то орган, его издавший, требовал исполнения указанных в них предписаний (в противном случае это грозило зачастую негативными последствиями). А в случае, если тот же гражданин (организация) обращались в суд, то органы исполнительной власти заявляли, что данные акты по своей природе не обладают юридической силой, а всего лишь разъясняют положения законодательства, тем самым «умывая руки». Получается весьма эффективная схема, при которой органы исполнительной власти могут заниматься своеобразным «нормотворчеством», при этом обходя судебные механизмы воздействия на подобную деятельность. А логическими результатами такого «правотворчества» являются:

1) нарушение прав граждан и организаций при участии в тех или иных правоотношениях;

2) своеобразное «перетягивание» функций по принятию общеобязательных правовых норм исполнительной властью, что в итоге приводит к искажению самой сути законодательных органов власти и принципа разделения властей в целом;

3) невозможность судебной ветви власти эффективно воздействовать на подобную деятельность.

Говоря о путях преодоления перечисленных нарушений и подытоживая исследование, то пред- ставляется возможным отметить следующее. Безусловно, описанные выше изменения, внесенные законодателем в Арбитражно-процессуальный кодекс и Кодекс административного производства, являются весьма позитивными, поскольку теперь оспаривание данных актов приобретает более строгий процессуальный порядок, что повышает возможности судебной власти реально влиять на «правотворчество» исполнительной власти и, что самое важное, эффективность защиты прав граждан организаций от данной деятельности.

Но, помимо процессуальной регламентации, необходимо также издание так называемого материального закона, который бы установил разновидности юридических актов, их соотношение по юридической силе между собой, толкование и т. д. В этом свете представляется вполне обоснованным и актуальным принятие Федерального закона «0 нормативных правовых актах», проект которого в настоящее время находится в МинЮсте России и который должен будет значительно помочь в разрешении проблем (как теоретических, так и практических), освещенных в настоящей статье. Например, что представляет собой НПА, какие могут быть его формы, какими существенными признаками он должен обладать. Также регламентировать вопросы принятия, изменения и утраты юридической силы НПА, их официальное толкование (разъяснение) и др. Но пока данный проект остается таковым, то изучение вопросов юридической природы различных нормативных и ненормативных актов порождает и будет порождать новые вопросы, которые потребуют более тщательного и глубокого исследования.

\section{Библиография:}

1. Определение Конституционного Суда Российской Федерации от 31.03.2015 г. № 6-П «По делу о проверке конституционности пункта 1 части 4 статьи 2 Федерального конституционного закона «0 Верховном Суде Российской Федерации» и абзаца третьего подпункта 1 пункта 1 статьи 342 Налогового кодекса Российской Федерации в связи с жалобой открытого акционерного общества «Газпром нефть»» // Российская газета. - 13 апреля 2015 г. № 6648.

2. Федеральный закон от 31.07.1998 г. N 146-ФЗ «Налоговый кодекс Российской Федерации» (ред. от 01.10 .2015 г.) // «Собрание законодательства Российской Федерации». 1998. № 31. Ст. 3824.

3. Постановление Правительства Российской Федерации от 13 августа 1997 г. N 1009 «Об утверждении Правил подготовки нормативных правовых актов федеральных органов исполнительной власти и их государственной регистрации» (ред. от 27.08.2015г.) // Российская газета. - 21.08.1997 г. № 161.

4. Приказ Министерства Юстиции Российской Федерации от 04.05.2007 г. № 88 «Об утверждении Разъяснений о применении Правил подготовки нормативных правовых актов федеральных органов исполнительной власти и их государственной регистрации» // Российская газета. - 24.05.2007 г. № 4371.

5. Решение Верховного Суда Российской Федерации от 10.07.2014г. № АКПИ14-735 «0 признании недействующим письма Министерства экономического развития РФ от 27 июля 2010 г. N 13293-ИМ/Д23 «Об основаниях аннулирования квалификационного аттестата кадастрового инженера»» // Российская газета. - 24.10.2014 г. № 244.

6. Марченко М. Н. Теория государства и права: учебник. - 2-е изд., перераб. и доп. / М. Н. Марченко. - М.: Проспект, 2013. $-656 \mathrm{c}$.

\section{References (transliterated):}

1. Opredelenie Konstitutsionnogo Suda Rossiiskoi Federatsii ot 31.03.2015 g. № 6-P «Po delu o proverke konstitutsionnosti punkta 1 chasti 4 stat'i 2 Federal'nogo konstitutsionnogo zakona «O Verkhovnom Sude Rossiiskoi Federatsii» i abzatsa 
tret'ego podpunkta 1 punkta 1 stat'i 342 Nalogovogo kodeksa Rossiiskoi Federatsii v svyazi s zhaloboi otkrytogo aktsionernogo obshchestva «Gazprom neft'»» // Rossiiskaya gazeta. - 13 aprelya 2015 g. № 6648.

2. Federal'nyi zakon ot 31.07.1998 g. N 146-FZ «Nalogovyi kodeks Rossiiskoi Federatsii» (red. ot 01.10.2015 g.) // «Sobranie zakonodatel'stva Rossiiskoi Federatsii». 1998. № 31. St. 3824.

3. Postanovlenie Pravitel'stva Rossiiskoi Federatsii ot 13 avgusta 1997 g. N 1009 «Ob utverzhdenii Pravil podgotovki normativnykh pravovykh aktov federal'nykh organov ispolnitel'noi vlasti i ikh gosudarstvennoi registratsii» (red. ot 27.08.2015 g.) // Rossiiskaya gazeta. - 21.08.1997 g. № 161.

4. Prikaz Ministerstva Yustitsii Rossiiskoi Federatsii ot 04.05.2007 g. № 88 «Ob utverzhdenii Raz"yasnenii o primenenii Pravil podgotovki normativnykh pravovykh aktov federal'nykh organov ispolnitel'noi vlasti i ikh gosudarstvennoi registratsii» // Rossiiskaya gazeta. - 24.05.2007 g. № 4371.

5. Reshenie Verkhovnogo Suda Rossiiskoi Federatsii ot 10.07.2014g. № AKPI14-735 «0 priznanii nedeistvuyushchim pis'ma Ministerstva ekonomicheskogo razvitiya RF ot 27 iyulya 2010 g. N 13293-IM/D23 «Ob osnovaniyakh annulirovaniya kvalifikatsionnogo attestata kadastrovogo inzhenera»» // Rossiiskaya gazeta. - 24.10.2014 g. № 244 .

6. Marchenko M. N. Teoriya gosudarstva i prava: uchebnik. - 2-e izd., pererab. i dop. / M. N. Marchenko. - M.: Prospekt, 2013. - $656 \mathrm{~s}$. 